Regards sur l'économie allemande

Bulletin économique du CIRAC

$103 \mid 2011$

Varia

\title{
Une avancée européenne majeure, mais à l'issue incertaine
}

René Lasserre

\section{OpenEdition}

Édition électronique

URL : http://journals.openedition.org/rea/4349

DOI : 10.4000/rea.4349

ISBN : 978-2-8218-1136-2

ISSN : 1965-0787

\section{Éditeur}

CIRAC

Édition imprimée

Date de publication : 16 décembre 2011

Pagination : 1-2

ISSN : 1156-8992

\section{Référence électronique}

René Lasserre, "Une avancée européenne majeure, mais à l'issue incertaine », Regards sur l'économie allemande [En ligne], 103 | décembre 2011, mis en ligne le 20 décembre 2011, consulté le 22

septembre 2020. URL : http://journals.openedition.org/rea/4349; DOI : https://doi.org/10.4000/rea 4349 


\section{Une avancée européenne majeure, mais à l'issue incertaine}

Après la laborieuse adoption, le 26 octobre dernier, du plan de sauvegarde et de solidarité financière de la zone Euro, l'accord que les chefs d'Etat et de gouvernement des pays membres de 1'UEM ont conclu le 9 décembre sur l'Union fiscale et budgétaire marque une avancée majeure sur la voie d'un gouvernement économique européen. Les dix-sept Etats se sont engagés sur la mise en œuvre d'une politique coordonnée de retour à l'équilibre des budgets nationaux et de réduction de la dette publique. Cette politique s'articulera autour d'objectifs précis et de règles strictes qui devront être inscrits dans leurs Constitutions respectives et donneront lieu à des sanctions lorsqu'ils ne seront pas respectés. En cas de déficits excessifs, des programmes d'urgence devront être mis en place dans les Etats membres concernés, avec l'approbation et sous le contrôle des autorités communautaires. L'ensemble de ces dispositions entreront en vigueur immédiatement et feront l'objet d'un traité qui devrait être formalisé d'ici mars 2012. Par ailleurs, la mise en œuvre des mécanismes prévus au Fonds de sauvegarde (FESF) est confiée à la responsabilité de la BCE et la mise en place, avec des moyens renforcés, du Mécanisme de Stabilité Européen (MES), préfiguration d'un Fonds monétaire européen, sera anticipée d'une année et entrera en vigueur en juin 2012. Ses interventions pourront être décidées à majorité qualifiée.

Avec ces mesures, l'UEM se voit enfin doter d'un véritable dispositif de gouvernance économique par lequel les Etats membres définiront conjointement, et par des mécanismes de consultation et de décision renforcés, une politique économique et financière concertée, comportant à la fois des engagements réciproques et des objectifs convergents, non seulement en matière de stabilité budgétaire mais également en matière d'harmonisation fiscale, de régulation financière et de compétitivité. On s'éloigne ainsi définitivement de la logique purement indicative et formaliste de l'ancien pacte de stabilité, qui en fait n'engageait personne mais décrédibilisait 1'Union et faisait artificiellement porter le doute sur une monnaie dont la force économique est incontestée.

Ce changement de paradigme ouvre la voie à une politique intégrée qui comportera certes des disciplines contraignantes, mais définies en fonction d'objectifs économiques tangibles qui feront l'objet d'une réelle négociation et engageront la responsabilité politique des Etats et des gouvernements. La politique européenne y gagnera indiscutablement en substance et en crédibilité. Il est de ce point de vue regrettable qu'on ait tant tardé. Et si le prix politique à payer est élevé au sein des Etats membres, il est à la mesure de la pusillanimité des gouvernements.

L'ascendance prise par la coopération intergouvernementale dans le contexte de la crise des institutions européennes puis de la crise économique et financière, et qu'il est désormais de bon ton de décrier en regrettant l'éclipse auto-générée des instances communautaires, n’apparaît 
à cet égard que comme un moindre mal. Ou du moins est-elle un mal nécessaire, et sans doute un passage obligé, si l'on veut que la politique européenne devienne réellement ce qu'elle est et ce qu'elle devrait être pour les citoyens européens, à savoir une composante à part entière de leur politique intérieure qu'ils doivent impérativement se réapproprier. Ceci implique que leurs gouvernements élus, au lieu de se défausser sur Bruxelles des mécontentements catégoriels, assument pleinement leur part de responsabilité communautaire dans la gestion de leur économie domestique. Ce n'est que lorsque cette logique de co-responsabilité aura été exercée au sein des Etats qui auront accepté de l'assumer, que des transferts de souveraineté pourront être progressivement consentis, ouvrant la voie à une gouvernance plus intégrée. Mais le chemin sera long et semé d'embûches.

Pour l'heure, en effet, nous n'en sommes pas encore là et, à la veille d'une échéance politique majeure, une incertitude politique plane à nouveau sur la capacité de la France à jouer pleinement son rôle pour relever ce nouveau défi historique de l'Europe. Alors que le président français, en dépit de toutes les improvisations qui ont réduit ses marges de manœuvre, s'est résolu à faire cause commune avec son partenaire allemand pour assurer le sauvetage de l'Euro, voici que son principal challenger à l'élection présidentielle récuse l'accord et dénonce par avance le Traité. Mais autant le choix de Nicolas Sarkozy a été lucide et courageux en ce qu'il a clairement jeté par-dessus bord à la fois sa vision quelque peu souverainiste de l'Europe et son libéralisme de façade englué dans le deficit spending, pour se convertir à une politique européenne intégrée de stabilité, autant son adversaire cède aux facilités de l'électoralisme le plus traditionnel.

Car il est tout de même dérisoire et consternant que, trente ans après le double choix historique que fit en 1983 François Mitterrand pour l'Europe et la stabilisation financière, son héritier socialiste présumé n'ait d'autre proposition que de mettre en avant le nécessaire soutien à la croissance pour laisser accroire aux Français que dans la situation actuelle on pourrait indéfiniment repousser l'assainissement budgétaire. Et que, par ailleurs, le même candidat laisse jouer autour de lui, et de manière peu discrète, le petit air de flûte détestable de l'Europe allemande. Décidément, et malgré l'épisode catastrophique du référendum de 2005, la France n'est pas complètement à l'abri, au sein d'une large frange de sa classe politique, d'une incartade européenne majeure.

René Lasserre, le 16 décembre 2011 